practice, I have given up trying to do sophisticated endocrine tests, and I conclude that others in a similar position should really question the wisdom of undertaking definitive assessment of the function of the hypothalamo-pituitary axis.

\section{Conclusion}

It is wrong to investigate a child growing at a normal

\section{Pharyngoconjunctival fever}

\author{
N GILADI AND J HERMAN
}

Family Medicine Clinic 'Gimmel', Beth She'an, Israel

SUMmaRY Sixteen infants and toddlers from four kibbutz day nurseries contracted an illness comprising fever, conjunctivitis, respiratory infection, lymphadenopathy, otitis media, and a new sign, migratory palpebral erythema. Adenovirus type 3 was isolated from the pharynx of the first three children taken ill.

Isolation of adenovirus was reported first in the United States in 1953. More than 30 serotypes are known and the virus may cause $10 \%$ of all febrile illness in children. ${ }^{1}$ We report an outbreak of pharyngoconjunctival fever affecting infants and toddlers in four day nurseries on a kibbutz in northern Israel. Type 3 adenovirus was isolated from three children and 13 other cases were diagnosed on clinical and epidemiological grounds. There was a high incidence of a hitherto unreported physical sign: migratory palpebral erythema.

\section{Patients}

Sixteen children, aged 4 to 20 months, contracted a febrile illness lasting an average of six days. All cases occurred between 24 December 1982 and 13 January 1983, the first two in one room of an infants' day nursery. Subsequently, an older brother of one of the infants, a toddler from a second nursery, was taken ill. His nurse was the mother of a child from a second room of the infants' house and the apparent means of spread there. Two toddlers whose mothers worked in the infants' house where the epidemic began, were affected next. They introduced it into two further nurseries where five more cases occurred. None of the adults became ill. rate but children who are growing slowly do require a test of growth hormone secretion, even if they are not absolutely short. Growth rate is a sufficient screening test but if growth hormone deficiency has to be excluded, a physiological test of growth hormone secretion should precede the full assessment of the hypothalamo-pituitary axis, unless that assessment is done in a centre which is regularly performing these investigations.

The clinical features of the 16 children included fever for an average of six days (range: 2 to 12 days), conjunctivitis (in 14), respiratory infection (11), pre-auricular and cervical lymphadenopathy (8), otitis media (5), and migratory palpebral erythema with oedema (8). Adenovirus type 3 was isolated from the pharynx, stool, and conjunctiva of one child and from the pharynx of two others.

\section{Discussion}

Pharyngoconjunctival fever caused by type 3 virus is thought to occur most often in older children and to be associated with contaminated swimming pools. The disease has been reported, however, in infant and toddlers, ${ }^{2}$ and respiratory shedding can be important to its spread. ${ }^{3}$ Conjunctivitis has been observed in 30 to $70 \%$ of patients with the disease $\mathrm{e}^{4}$ making the incidence of $88 \%$ reported here unusually high. There was evidence of respiratory infection in $69 \%$ of our patients, with wheezing and coarse rales frequently present, contrary to the general belief that bronchitis is rare. ${ }^{15}$

Oedema of the eyelids has been described in pharyngoconjunctival fever ${ }^{4}$ but migratory erythema, which was seen in $50 \%$ of our patients, has not. In some instances the entire upper lid was red and swollen, in others the erythema was noticed first at the medial half of the lid, extending towards the bridge of the nose and mimicking the findings in ethmoiditis. In a few patients the erythema migrated to the inner part of the lower lid, as in dacryocystitis, or to the outer portion of the upper lid, as in dacryoadenitis.

The means of contagion is uncertain. Droplet infection seems likely, but it has been shown that it? is virtually impossible to produce pharyngoconjunc- 
tival fever by inoculating adenoviruses into the nose or throat, whereas swabbing them onto the conjunctiva leads to events closely paralleling the naturally occurring disease. ${ }^{2}$ Furthermore, the efficacy of large and small particle aerosol spread of rhinovirus over a range of $70 \mathrm{~cm}$ is low in comparison with hand to hand contact. ${ }^{6}$ The cribs in the infants' house are farther apart than $70 \mathrm{~cm}$ and it seems unlikely that droplets propelled by coughing or sneezing could reach the conjunctival sac of an infant in an amount sufficient to produce infection.

The fact that three healthy adults were implicated in the spread of disease from one wing to another of the infants' house and also to two nurseries raises the possibility of hand to eye transmission. At night the children sleep at home where infants, who do not have intimate contact with one another during the day, have prolonged and close association with parents and siblings. Thus, a family containing both an infant and a toddler was probably a key link in the chain of infection. The three mothers who worked as nurses in the infants' house and in the first nursery affected could have transmitted the infection while bathing the children under their care or wiping away eye or nose secretions.

Finally, the fact that the outbreak was confined to infants and toddlers, aged 4 to 20 months, despite ample exposure through intimate household contact with older age groups, requires explanation. Earlier experience has shown that secondary family attack rates for type 3 adenovirus decrease with age, which implies that adults and older children may have been infected previously with resultant prolonged immunity. ${ }^{2}$ This could account for the limited spread of pharyngoconjunctival fever recorded here.

We thank Dr L Ranon of the Central Virus Laboratory, Ministry of Health, Israel, the nurses of Kibbutz Tirat Zvi, and C Wendel, for secretarial assistance.

\section{References}

1 Baum SG. Adenovirus. In: Mandel GL, Douglas RG, Bennett KE, eds. Principles and practice of infectious diseases. New York: John Wilcy \& Sons, 1979:1353-61.

2 Bell JA. Epidemiology of pharyngoconjunctival fever. $A m J$ Ophthalmol 1957:43:36-40.

${ }^{3}$ Fox JP. Hall CE, Cooney MK. The Seattle virus watch. VII. Observations of adenovirus infection. Am $J$ Epidemiol 1977; 105:362-86.

${ }^{4}$ Germanis M. Jeansson S. Ocular illness in association with adenovirus type 3 infection. Scand J Infect Dis 1973:5:243-8.

5 Kendall EJC, Riddle RW. Tuck HA, Rodan KS. Andrews BE, McDonald JC. Pharyngo-conjunctival fever. School outbreaks in England during the summer of 1955 associated with adenovirus types 3, 7 and 14. Br Med J 1957:ii:129-36.

${ }^{6}$ Gwaltncy JM, Moskalski PB, Hendley JO. Hand-to-hand transmission of rhinovirus colds. Ann Intern Med 1978;88: 463-7.

Correspondence to Dr J Herman, Kibbutz Tirat Zvi, Beth She'an Valley 10815, Isracl.

Received 17 July 1984

\title{
Successful treatment of severe carbamyl phosphate synthetase I deficiency
}

\author{
M VAN DE BOR, P MOOY, D VAN ZOEREN, R BERGER, H H VAN GELDEREN, \\ AND H L TEIJEMA
}

Departments of Paediatrics, University Hospitals Leiden and Groningen, The Netherlands

\begin{abstract}
SUMMARY We describe a girl with neonatal hyperammonaemia due to carbamyl phosphate synthetase I deficiency. Treatment consisted of protein restriction from the second day of life. Sodium benzoate was given for three weeks after birth and again from 7 months of age together with sodium phenylacetate to improve protein tolerance. Growth and development are normal at 15 months of age.
\end{abstract}

In carbamyl phosphate synthetase I deficiency the urea cycle enzyme that converts ammonia to carbamyl phosphate is deficient, leading to hyperammonaemia. Patients with little or no enzyme activity (neonatal form) present with vomiting, lethargy, seizures, and coma; death normally ensues in the first week of life, but three patients have survived for six, eight, and 15 months respectively. ${ }^{1}$ In patients with a partial defect these symptoms may be less severe or delayed until later in infancy and usually result in mental retardation and major neurological defects.

Treatment of carbamyl phosphate synthetase I 